\title{
Changes in cerebellar activity and inter-hemispheric coherence accompany improved reading performance following Quadrato Motor Training
}

\author{
Tal Dotan Ben-Soussan ${ }^{1,2}{ }^{*}{ }^{\dagger}$, Keren Avirame ${ }^{1,3+}$, Joseph Glicksohn ${ }^{1,4}$, Abraham Goldstein ${ }^{1,5}$, Yuval Harpaz ${ }^{1}$ \\ and Michal Ben-Shachar ${ }^{1,6}$
}

${ }^{1}$ The Leslie and Susan Gonda (Goldschmied) Multidisciplinary Brain Research Center, Bar-llan University, Ramat-Gan, Israel

${ }^{2}$ Research Institute for Neuroscience, Education and Didactics, Cognitive Neurophysiology Laboratory, Patrizio Paoletti Foundation, Assisi, Italy

${ }^{3}$ Department of Neurology, Charité - Universitätsmedizin, Berlin, Germany

${ }^{4}$ Department of Criminology, Bar-llan University, Ramat-Gan, Israel

${ }^{5}$ Department of Psychology, Bar-Ilan University, Ramat-Gan, Israel

${ }^{6}$ Department of English, Linguistics Division, Bar-llan University, Israel

\section{Edited by:}

Mikhail Lebedev, Duke University, USA

\section{Reviewed by:}

Froylán Gómez-lagunas, UNAM, Mexico

Panagiotis D. Bamidis, Aristotle University of Thessaloniki, Greece

\section{*Correspondence:}

Tal Dotan Ben-Soussan, Research Institute for Neuroscience,

Education and Didactics, Cognitive Neurophysiology Laboratory,

Patrizio Paoletti Foundation, via

Cristoforo Cecci 2, 06081 - Santa

Maria degli Angeli, Assisi (PG), Italy e-mail:

research@fondazionepatriziopaoletti.org

${ }^{\dagger}$ These authors have contributed equally to this work.
Dyslexia is a multifactorial reading deficit that involves multiple brain systems. Among other theories, it has been suggested that cerebellar dysfunction may be involved in dyslexia. This theory has been supported by findings from anatomical and functional imaging. A possible rationale for cerebellar involvement in dyslexia could lie in the cerebellum's role as an oscillator, producing synchronized activity within neuronal networks including sensorimotor networks critical for reading. If these findings are causally related to dyslexia, a training regimen that enhances cerebellar oscillatory activity should improve reading performance. We examined the cognitive and neural effects of Quadrato Motor Training (QMT), a structured sensorimotor training program that involves sequencing of motor responses based on verbal commands. Twenty-two adult Hebrew readers (12 dyslexics and 10 controls) were recruited for the study. Using Magnetoencephalography (MEG), we measured changes in alpha power and coherence following QMT in a within-subject design. Reading performance was assessed pre- and post-training using a comprehensive battery of behavioral tests. Our results demonstrate improved performance on a speeded reading task following one month of intensive OMT in both the dyslexic and control groups. Dyslexic participants, but not controls, showed significant increase in cerebellar oscillatory alpha power following training. In addition, across both time points, inter-hemispheric alpha coherence was higher in the dyslexic group compared to the control group. In conclusion, the current findings suggest that the combination of motor and language training embedded in OMT increases cerebellar oscillatory activity in dyslexics and improves reading performance. These results support the hypothesis that the cerebellum plays a role in skilled reading, and begin to unravel the underlying mechanisms that mediate cerebellar contribution in cognitive and neuronal augmentation.

Keywords: dyslexia, MEG, motor training, cerebellum, alpha power, coherence, reading

\section{INTRODUCTION}

Reading is a basic ability necessary in every-day life. Failure to acquire literacy early in the schooling years may have serious consequences for an individual's academic achievements, wellbeing and employment prospects. Dyslexia, which is characterized by difficulties with accurate and fluent word recognition, poor spelling and decoding abilities, is the most common learning disability, with a prevalence rate of about $10 \%$ in school-age children (Deffenbacher et al., 2004). Longitudinal studies further indicate that dyslexia is a chronic condition that persists into adulthood (Shaywitz et al., 2008).
Difficulties in learning to read are commonly thought to derive from impaired phonemic representations and phonological processing (Bradley and Bryant, 1983; Ramus, 2004). This phonological deficit has been associated with aberrant cortical responses and altered asymmetry of activity in frontal and temporal language- and reading-related areas (Ramus, 2004; Dufor et al., 2007; Gabrieli, 2009), as well as with structural and functional abnormalities of the cerebellum (Pernet et al., 2009b).

The involvement of the cerebellum in higher cognitive functions such as language was once a controversial issue (Leiner et al., 1993; Rao et al., 2001). However, much evidence has 
been gathered in recent years to support this view. Initially, studies in patients with cerebellar disease reported significant deficits in verbal fluency (Akshoomoff et al., 1992; Appollonio et al., 1993). Later, cerebellar involvement was found in other aspects of language, such as phonological and semantic processing (for reviews see Stoodley and Schmahmann, 2009; Stoodley and Stein, 2011). In addition, structural imaging demonstrated that lower cerebellar declive volumes are associated with impaired reading abilities, suggesting that the cerebellum may be a biomarker of dyslexia (Pernet et al., 2009b). In fact, the cerebellar and frontal differences between dyslexics and controls are the most consistent (for reviews see Pernet et al., 2009a,b). For example, Eckert et al. (2003) found that the volume of the right anterior lobe of the cerebellum significantly distinguished dyslexic from control participants, and was correlated with reading measured by a singleword reading task.

According to broader theories, dyslexia is not limited to phonological difficulties but encompasses a wide range of neurodevelopmental deficits that can be traced back to the sensorimotor systems (Stein, 2001; Galaburda et al., 2006). It follows that difficulties in phonological processing related to dyslexia are secondary to impairments in basic sensory and motor processing. Some posit an impairment at an early stage in which fast incoming sensory information is processed in the magnocellular system (Stein and Walsh, 1997), while others have suggested a fundamental deficit in the integration of rapidly successive transient signals (Tallal et al., 1996) or in the detection of regularities in sound sequences (Oganian and Ahissar, 2012). These approaches all put forward the premise that sensorimotor alterations might be the source of the core reading impairments observed in dyslexia.

Although the role of the motor system in dyslexia is still controversial, it is by no means a novel proposal that dyslexia involves a motor component. Already in the 1930's, Orton observed abnormal clumsiness in dyslexic children. He suggested that clumsy children could have difficulties in learning complex body movements as well as movements which are necessary for speech and writing (Orton, 1937). Studies of dyslexic participants have found impaired motor performance in a variety of tasks such as speed of tapping, heel-toe placement, rapid successive finger opposition, accuracy in copying, learning and execution of motor sequence (Nicolson et al., 2001; De Kleine and Verwey, 2009). This body of evidence supports the claims regarding the functional interactions between motor control systems, language and reading (for reviews see Hickok et al., 2011; Buckner, 2013).

The importance of cerebellar oscillatory function in neuroplasticity (Swinnen, 2002; De Zeeuw et al., 2011) and its role in motor acquisition, such as bimanual skills (e.g., Andres et al., 1999), have long been acknowledged in studies related to motor learning. Since impaired motor skills were often observed in dyslexics, some researchers attributed dyslexics' cognitive and motor deficiencies to abnormal development and functioning of the cerebellum (Nicolson et al., 1999, 2001). These findings lead to the claim that the role of the cerebellum is not limited to regulating the rate, force, rhythm, and accuracy of movements, but also the speed, capacity, consistency and appropriateness of cognitive processes (Schmahmann, 2004; Hölzel et al., 2011; Buckner, 2013).
Consequently, several training studies aimed to improve reading through integrated sensory stimulation, incorporating visuomotor and vestibular home-based exercise program lasting 6 months (Reynolds et al., 2003; Reynolds and Nicolson, 2007). In their study, the intervention group improved in a range of motor skills, such as cerebellar/vestibular and eye movement tests, as well as in the Dyslexia Screening Test, more than the control group. Although the authors could only speculate about the neural mechanisms underlying these motor and cognitive improvements, they pointed to the involvement of cerebellar function in mediating these behavioral changes. In order to improve reading and spelling in dyslexia, other studies investigated the effect of normalizing oscillatory activity on reading and spelling using neurofeedback (Breteler et al., 2010). Following 10 weeks of neurofeedback training, the intervention group showed improved spelling in contrast to the control group; however, no improvement was found in reading performance in either group. In addition, a significant increase in alpha coherence was found, which was interpreted as an indication that attentional processes account for the observed improvement in spelling, while no correlation was found between the two measures. So far, the link between training-induced changes in cerebellar alpha oscillatory activity and reading skills remained unexplored.

In the current study, we explore the possible potential interactions between sensorimotor and reading systems, and the role of the cerebellum as a mediator between them. In a preliminary attempt to understand the causal relationship between these constructs and their role in dyslexia, we examined how reading skills change as a result of a highly-structured form of sensorimotor training. We applied Quadrato Motor Training (QMT), a new sensorimotor whole-body training that involves following a structured set of simple oral instructions, by stepping to the instructed corner in a square. Recently, we demonstrated that one session of QMT can improve cognitive function, including creativity and spatial cognition, in comparison to two alternative training regimens that did not combine motor and cognitive aspects (Ben-Soussan et al., 2013, 2014). In the current study, the QMT is applied for a period of one month, in order to test its efficacy in inducing plasticity.

We have chosen magneto-encephalography (MEG) as the main tool for assessing changes in brain activity, due to its excellent resolution in the temporal domain, as well as its superiority to EEG in terms of effective spatial resolution (Kanda et al., 2000; Genow et al., 2004). In fact, it has been explicitly argued that MEG could be an excellent tool for evaluating the neural correlates of training-induced changes in dyslexia because of its ability to localize the sources of the alpha activation in parallel to the examination of long-distance alpha coherence (Salmelin, 2007). Further theoretical motivation for this choice is provided by the temporal sampling framework (TSF), which has been recently proposed to connect the observed sensorimotor deficits in dyslexia to temporal alterations in neuronal oscillations (Goswami, 2011). We therefore set out to examine the effects of QMT in a group of adult dyslexics and matched controls using MEG alpha power and coherence as electrophysiological dependent measures, as well as reading performance and verbal fluency as cognitive measures. 
We hypothesized that dyslexics would show reduced alpha power, altered alpha coherence and lower reading skills at baseline in comparison to controls. We further hypothesized that QMT would increase cerebellar alpha power due to the important role of cerebellar alpha power in voluntary action (Tesche and Karhu, 2000; Ivry et al., 2002). Increased cerebellar alpha power would then serve to normalize alpha coherence (Basar et al., 1997; Andres et al., 1999; Silberstein et al., 2003; Silberstein, 2006; Güntekin and Basar, 2010) and improve reading (Goswami, 2011). We therefore tested whether a 4-week period of daily QMT would: (a) Enhance alpha power and normalize alpha coherence in dyslexic adults; (b) Enhance reading performance. Finally, we tested whether changes in alpha power and interhemispheric alpha coherence would correlate with behavioral changes in reading.

\section{METHODS}

\section{PARTICIPANTS}

Twenty-two native Hebrew speakers participated in the study: 12 dyslexic participants ( 5 females and 7 males; mean age $=30( \pm 6)$; years of education $=15( \pm 1))$ and 10 controls $(7$ females and 3 males; mean age $=27( \pm 5)$; years of education $=14( \pm 2))$.
We recruited volunteers who had been previously diagnosed as dyslexic by a clinical or educational psychologist and had a documented history of reading and spelling difficulties. We excluded participants who were further diagnosed with comorbid disorders, including Attention Deficit Hyperactivity Disorder (ADHD), Attention Deficit Disorder (ADD) and developmental coordination disorder (Ramus et al., 2003). All participants provided written informed consent to take part in the study.

\section{PROCEDURE}

The study included three phases: pre-training assessment, QMT training, and post-training assessment (See Figure 1). The pretraining session (Day 1) included the following components in this fixed order: (a) Cognitive testing (about $30 \mathrm{~min}$, see Section Cognitive Tasks below); (b) MEG measurements (about 15 min, see Section MEG Data Acquisition below); and (c) QMT training (about $7 \mathrm{~min}$, see Section Quadrato Motor Training below). Post-training assessment took place at the lab on Day 29, and included the cognitive and MEG components as on Day 1 in the same order using matched versions of the cognitive tasks (see Section Cognitive Tasks). Due to technical problems, one dyslexic participant did not complete the behavioral tasks; additionally,

A

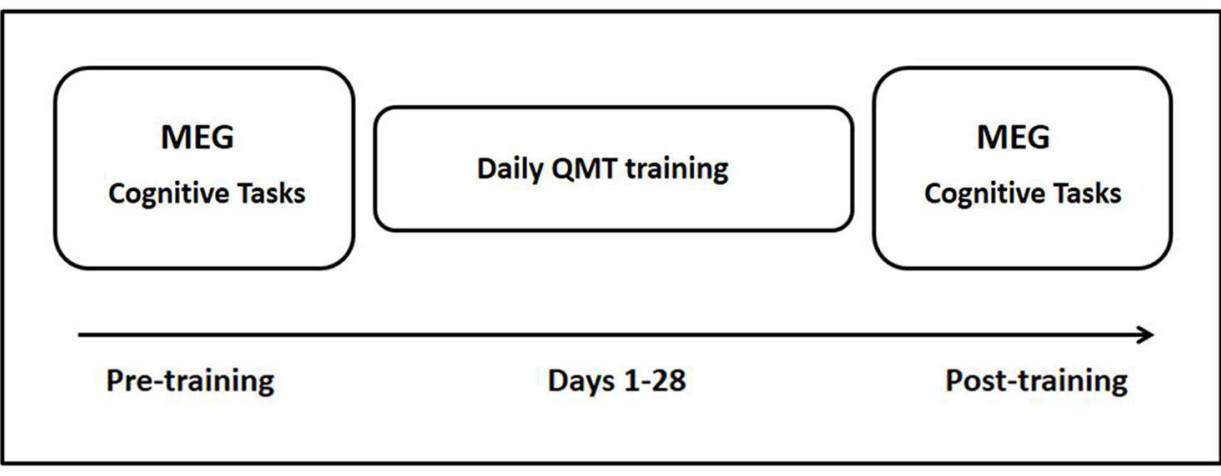

B

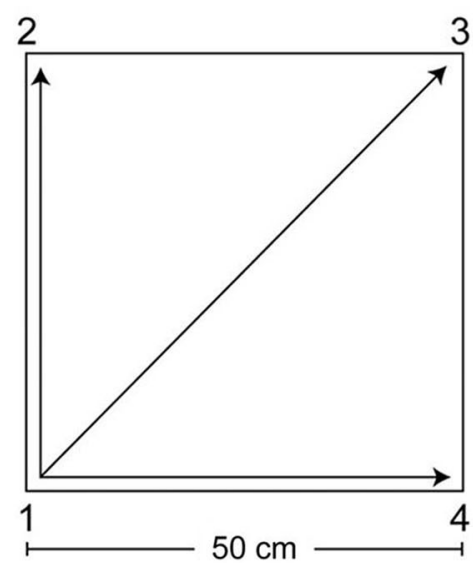

C

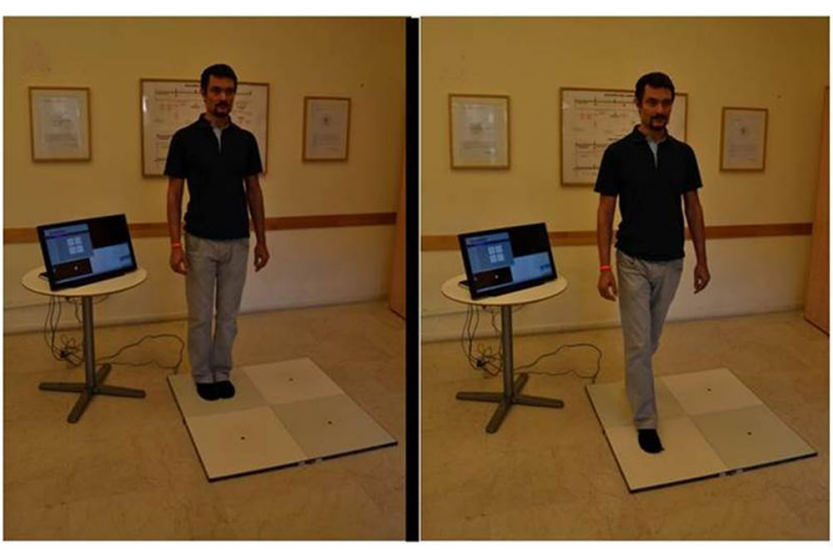

FIGURE 1 | Study design and Quadrato Motor Training. (A) Experimental protocol. MEG and behavioral measurements were conducted before and after 4 weeks of QMT training (see text for details). Two different versions of the cognitive tests were presented pre- and post-training in a counterbalanced order. (B) The spatial layout of the training space. (C) Practice setup. The trainee listens to recorded instructions and takes a step towards the target point. Figure adapted from Ben-Soussan et al. (2014). Quadrato Motor Training = QMT; Magnetoencephalography = MEG. 
the behavioral data for the post-training verbal fluency tasks was incomplete for two dyslexic and one control participants. In those cases where participants failed to complete certain behavioral tests, their MEG measurements were still included in the analysis of the MEG data in order to increase statistical power given the small sample size.

\section{QUADRATO MOTOR TRAINING}

The participant stood in a quiet room at one corner of a 0.5 $\mathrm{m} \times 0.5 \mathrm{~m}$ square and made movements in response to verbal instructions given by an audio tape recording. Participants were instructed to keep the eyes focused straight ahead and their hands loose at the side of the body. They were also told to immediately continue with the next instruction and not to stop due to mistakes. At each corner, there are three possible directions to move. The training thus consists of 12 possible movements (Figure 1). The daily training consisted of a sequence of 69 commands, lasting $7 \mathrm{~min}$. Two variables that were addressed in other studies of motor learning are limb velocity and the decision regarding the responding limb (Criscimagna-Hemminger et al., 2002; Donchin et al., 2003). In order to control these parameters, we used a movement-sequence paced at a rate of an average of $0.5 \mathrm{~Hz}$ (similar to a slow walking rate), and we instructed the participants to begin all movements with the leg closest to the center of the square. Starting on day 2, daily QMT sessions were conducted by the participants at home. Home training lasted 27 consecutive days (from Day 2 to Day 28), and lasted 7 min each day.

\section{COGNITIVE TASKS}

The cognitive tasks were performed before the MEG measurement, and lasted for about $30 \mathrm{~min}$. The order of tasks was fixed, starting with the reading test, category-based fluency and then letter-based fluency task. Each task had two different versions, and each of these versions was assigned to the pre- or post-training session in a counterbalanced manner across subjects.

\section{Reading test}

This test examines single-word reading speed and accuracy. A list of forty five written Hebrew words of increasing difficulty was presented and participants were asked to accurately read as many words as possible from the list in $1 \mathrm{~min}$. The level of difficulty of the words was controlled in terms of word length and number of syllables. In order to minimize learning effects from the pretest to the post-test, two non-overlapping word lists were created. Each list was presented either before or after training, in a counterbalanced manner. The two lists of 45 words were sampled from a database of rated Hebrew words (Levy-Drori and Henik, 2006), and were matched item-by-item for concreteness, availability of context, familiarity, number of letters and number of syllables. Since several participants from the control group finished the list of words in less than $1 \mathrm{~min}$, the final score represents the number of words which were read correctly in the first $30 \mathrm{~s}$.

\section{Category-based fluency task}

Participants were asked to say in $1 \mathrm{~min}$ as many words as possible belonging to a given semantic category. Two semantic categories were used alternately: (a) Animals; (b) Fruits and vegetables. One category was presented in the pre-training session (Day 1) and the other in the post-training session (Day 29), and the order of the categories was counterbalanced across subjects. Fruits and vegetables were treated as one category in order to avoid the ambiguity between botanical definitions and common usage (as in "avocado"). These categories were chosen because they have comparable norms, and in order to avoid test-retest influence by repeating the same category (Kavé, 2005).

\section{Letter-based fluency task}

Participants were asked to say in one minute as many words as possible that start with a given letter. We used two Hebrew letters: Bet $(/ \mathrm{b} /)$ and Gimel $(/ \mathrm{g} /)$. One letter served for pre-training and the other for post-training, and the order of the categories was counterbalanced across subjects. These letters were chosen because they have comparable norms, and in order to avoid testretest influence by repeating the same letter (Kavé, 2005).

\section{MEG DATA ACQUISITION}

Power and coherence measures were collected using the MEG at the beginning and at the end of the month, after performing the cognitive tasks. MEG recordings were conducted with a whole-head 248-channel magnetometer array (4-D Neuroimaging, Magnes $3600 \mathrm{WH}$ ) in a magnetically shielded room. During the Rest condition, the participants were asked to refrain from moving and from falling asleep. In addition, the participants were asked to keep their eyes closed, in order to reduce ocular artifacts in the measured signals and to facilitate the localization of potential generator regions of the alpha restingstate oscillations (Goldman et al., 2002). Data acquisition took 15 min. We also collected MEG data using two active tasks which will be reported elsewhere. Before acquiring the data, the head-shape of each subject was digitized. Reference coils located approximately $30 \mathrm{~cm}$ above the head oriented by the $x$, $y$ and $z$ axes were used to record environmental noise. Three accelerometers, one for each axis, attached to the MEG gantry were used to record building vibrations in order to remove artifacts caused by them. The data were digitized at a sampling rate of $1017.25 \mathrm{~Hz}$, and a 0.1 to $400 \mathrm{~Hz}$ band-pass filter was used online. The $50 \mathrm{~Hz}$ line power fluctuations were recorded directly from the power-line in order to remove the artifact on the MEG sensors.

\section{PREPROCESSING MEG DATA}

Power line, heartbeat, and vibration artifacts were removed automatically (Tal and Abeles, 2013). The data were then divided into $1 \mathrm{~s}$ epochs. Muscle artifact was estimated by examining the absolute value of all the MEG channels for every epoch, after applying a $20 \mathrm{~Hz}$ high-pass filter. For each epoch, the mean absolute value was computed. These values were then converted to z-scores, and epochs with $z$-scores greater than 3 standard deviations were rejected. Eye blinks were not considered as possible artifact for the alpha power processing, because the participants had their eyes closed and did not blink. Some eye movement artifact was still present in the data, but this was in a lower frequency range and was negligible in the alpha frequency range. Two of the 248 
channels were noisy (one of the channels registered a constant zero value and the other exceeded 1 nanotesla); these channels were therefore excluded from all sensor and source level analysis. For left-right coherence computation, their homolog channels were omitted as well.

\section{SOURCE LOCALIZATION}

Source localization was applied for the alpha $(7-13 \mathrm{~Hz})$ frequency band. Synthetic Aperture Magnetometry (SAM) beamforming (Robinson and Vrba, 1999) was used with multiple spheres forward solution based on the digitized headshape. The neural activity was estimated for a grid of points covering the volume of the brain with $5 \mathrm{~mm}$ intervals. The power of activity was calculated for every grid point and for every epoch. Since raw beamforming results are biased toward deep sources it was necessary to normalize the images in order to keep the noise level equal throughout the whole volume of the brain. For this purpose, a pseudo- $z$ score was calculated by averaging the power of every location, across epochs, divided by its noise estimate. The noise estimate was determined by the weights (the spatial filter). Deep sources generally have weights with higher values and are therefore noisier. Dividing the power of activity by the square of the weight norm can compensate for this bias (see Equation 3 in Sekihara et al., 2004). The absolute value of the weights of a particular location serves as a noise estimate. The resulting images represent the increase of alpha compared to noise, without being biased to deep sources. The pseudo- $z$ value for each location was visualized as the color of voxels in the resulting functional images. The images were transformed to Talairach space by fitting a template MRI to the individual headshapes using SPM8 (Friston et al., 2007) and FieldTrip (Open Source Software for Advanced Analysis of MEG, Oostenveld et al., 2011) packages used with Matlab ${ }^{\circledR}$ R2010b. In order to control for multiple comparisons, a simulation was applied using an Analysis of Functional NeuroImages (AFNI) function (AlphaSim) which determines the probability to get significant clusters of different sizes at random. According to the simulation, at current parameters (given the template brain and spatial resolution used), clusters of voxels with a $p$-value smaller than 0.05 and exceeding one cubic $\mathrm{cm}$ ( 8 voxels) do not count as random noise. We decided to be even more conservative and to take only clusters containing more than 20 voxels at a threshold of $p<0.005$ (Bunge et al., 2001).

\section{COHERENCE}

The coherence between left and right sensors was computed using FieldTrip. The data were first baseline-corrected by subtracting the mean of every epoch from the MEG traces. Eighteen channels located along the midline of the helmet were omitted from the coherence analysis, because these channels are likely to present with high coherence based on proximity, since spatially close sensors are likely to pick up very similar activities (Lehnertz et al., 2014).

Fourier transform was then computed using a spectral smoothing box of $1 \mathrm{~Hz}$ (meaning that the $10 \mathrm{~Hz}$ bin includes 9 to $11 \mathrm{~Hz}$ oscillations). The frequencies per time window were computed using a DPSS bell-shaped window. The resulting complex spectrum was used to assess coherence between each channel and its homolog. The coherence value of the 18 channels located along the mid-line of the helmet was set to one, representing perfect coherence between each channel and itself (the vertical red line in Figure 4). The coherence was projected onto a twodimensional map of the sensor array, using the same left-right coherence value for the left as well as the right sensor, thus creating symmetrical maps of coherence. After the creation of the maps, channels close to the midline were excluded from the statistical analysis (in addition to the midline channels). This step was necessary because channels near the midline had high coherence values which did not represent cortical coherence, but simply the fact that the activity of one brain region was measured by two nearby channels. The channel pairs chosen were at least $11 \mathrm{~cm}$ apart in order to avoid "false coherence" resulting from close channels that pick up the same source and covered the lateral area of increased coherence (greater than 0.3; Figure 4). This procedure resulted in 59 channel pairs for which left-right coherence was statistically evaluated. Usually when studying interhemispheric differences, coherence is computed for one artifactfree channel for each region (e.g., from frontal, central, parietal, and temporal regions) and is computed for channels located in the corresponding regions of the two hemispheres (Osipova et al., 2003; Kikuchi et al., 2011). In fact, the number of chosen pairs is conventionally determined by apriori assumptions and therefore restricted to particular regions of interest. However, due to the exploratory nature of the current study, it was important to expand the search across multiple sensors.

\section{STATISTICAL ANALYSIS}

Mixed design ANOVA was used to test the effects of QMT on performance in the reading and verbal fluency tasks, with Training (pre-training, post-training) as a within-subject factor and Group (dyslexic, control) as a between-subjects factor. Statistical parametric maps were produced from MEG data using the AFNI package (Cox, 2012). Mixed design ANOVA was used to test the effects of QMT on alpha activity, i.e., alpha power and alpha coherence. Pearson correlation was used to test the association between behavioral and neuronal changes. The correlation threshold was $p<0.05$. Post hoc comparisons were conducted using $t$-tests.

\section{RESULTS \\ COGNITIVE RESULTS Reading task}

Performance on the speeded reading task was entered into a 2 (Group) by 2 (Training) ANOVA. First, a significant main effect for Group $\left[F_{(1,19)}=7.80, p<0.05\right]$ was observed, indicating that, across both time points, the number of words correctly read by the controls $(M=38.5, \mathrm{SD}=6.3)$ was higher than the number of words correctly read by the dyslexic participants $(M=27.6, \mathrm{SD}=$ 10.7). Secondly, the analysis yielded a main effect for Training $\left[F_{(1,19)}=6.89, p<0.05\right]$, showing that QMT improved singleword reading performance across both groups (see Figure 2). Finally, the interaction between Training and Group was not significant $(p>0.9)$. 


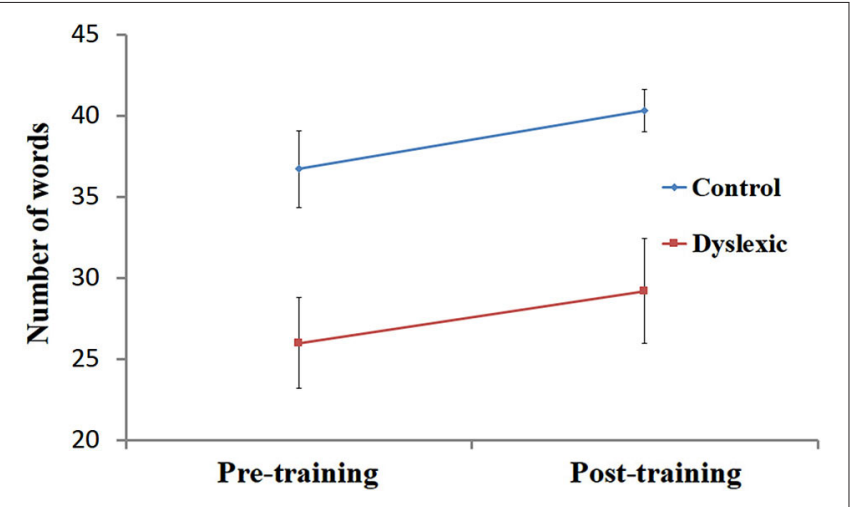

FIGURE 2 | Reading performance pre- and post-training. Number of words read correctly (mean \pm SEM) in $30 \mathrm{~s}$, pre- and post-training in the dyslexic (red) and control (blue) groups.

\section{Verbal fluency}

We conducted two separate analyses for the category-based and letter-based fluency tasks using a 2 (Group) by 2 (Training) ANOVA. No significant main effects or interactions were found, for either the category-based or the letter-based fluency task. The mean scores (i.e., number of words generated in $1 \mathrm{~min}$ ) of the control participants for the category-based or letter-based fluency were similar to the norms (Kavé, 2005).

Based on previous studies demonstrating significant differences in phonological fluency between dyslexic and controls (Rack et al., 1992; Reid et al., 2007), we conducted a planned comparison between the groups for letter-based fluency, separately for pre- and post-QMT. While a marginally significant difference in phonological fluency was found pre-training between the dyslexic and control groups $\left[t_{(19)}=2.08, p=0.051\right]$, no such difference was found following the training. In addition, no differences were found between the groups in semantic fluency, neither before nor after training. See Table 1.

\section{MEG RESULTS}

\section{Between-group differences in cerebellar alpha power}

We first examined the effect of QMT on alpha power using a mixed design ANOVA, with Training as a within-subject factor and Group (Dyslexia, Control) as a between-subjects factor, for each voxel. The ANOVA revealed a significant Group $\times$ Training interaction in a cluster in the right cerebellum. The center of mass of this cluster was located in the right culmen (Talairach coordinates (in mm): $12,-37,-22 ; F_{(1,20)}=13.3, p<0.0025$; See Figure 3A). Before training, cerebellar alpha power was significantly lower in the dyslexic group compared to the control group $\left(t_{(20)}=3.88, p=0.001\right)$. Following 4 weeks of daily QMT, cerebellar alpha power significantly increased in the dyslexic group $\left(t_{(11)}=3.08, p=0.01\right)$ in contrast to the control group which showed no significant change following training (see Figure 3B).

The ANOVA also revealed a significant Group $\times$ Training interaction for three frontal clusters, located in the right superior frontal gyrus (SFG) (Talairach coordinates in $(\mathrm{mm}): 23,53,17)$ $\left[F_{(1,20)}=16.08, p<0.001\right]$, supplementary motor area (SMA)
Table 1 | Mean scores of letter-based and category-based fluency tasks as a function group and training.

\begin{tabular}{lcccccccc}
\hline & \multicolumn{3}{c}{ Letter } & \multicolumn{5}{c}{ Category } \\
\hline & Pre & & Post & & Pre & & Post & \\
& Mean & SD & Mean & SD & Mean & SD & Mean & SD \\
Dyslexic & 8.7 & 2.4 & 9.0 & 1.9 & 23.9 & 5.2 & 24.9 & 4.3 \\
Control & 10.9 & 3.1 & 10.4 & 2.1 & 23.8 & 5.1 & 25.6 & 4.0 \\
\hline
\end{tabular}

(Talairach coordinates in $(\mathrm{mm}): 13,18,42)\left[F_{(1,20)}=22.41, p<\right.$ 0.001 ] and the left middle frontal gyrus (Talairach coordinates in $(\mathrm{mm}):-27,8,57)\left[F_{(1,20)}=16.01, p<0.001\right]$. While there were no significant differences between the groups in these areas prior to training, the control group showed a significant decrease in alpha power in the left medial frontal gyrus (MFG) $\left(t_{(9)}=4.54\right.$, $p<0.005)$, right SFG $\left(t_{(9)}=3.73, p<0.005\right)$ and SMA $\left(t_{(9)}=\right.$ $3.69, p<0.005)$ following 4 weeks of daily QMT. On the other hand, the opposite pattern was observed in the dyslexic group in which alpha power increased in the right SFG $\left(t_{(11)}=2.66, p<\right.$ 0.05).

\section{Coherence}

Inter-hemispheric alpha coherence was tested using a mixed design 2-way ANOVA for each of the 59 channels, with Training as within-subject factor and Group as between-subjects factor. Across both time points, inter-hemispheric alpha coherence was significantly higher in the dyslexic group compared to the control group for five channel pairs $\left(F_{(1,21)}>8.35, p<0.01\right.$, uncorrected; See Figure 4). No main effect for Training or interaction was found.

\section{Neuro-cognitive correlations}

In order to study the possible associations between change in alpha activity and change in reading performance, we calculated Pearson correlations between behavioral and neuronal change within each group. This analysis was motivated by previous studies relating reading, cerebellar activity and alpha coherence (Nicolson et al., 2001; Weiss and Mueller, 2003; Arns et al., 2007). Change in speeded reading was calculated as the difference between the number of words read correctly in $30 \mathrm{~s}$ before and after training. Change in cerebellar alpha power was calculated as the difference between pre- and post- training cerebellar alpha power of the cluster which was found to have the significant Group $\times$ Training interaction. Change in inter-hemispheric alpha coherence was calculated as the difference between pre- and posttraining values of the bilateral temporal alpha coherence. No significant correlation was found between change in cerebellar alpha power and change in reading in the two groups. Yet, as can be seen in Figure 5, change in temporal alpha coherence was positively correlated with the change in reading score $(r=0.58$, $p<0.05, n=11$; uncorrected) in the dyslexic group but not in the control group. Using the Fisher $r$-to- $z$ transformation, we calculated the $z$ value to assess the significance of the difference between two correlation coefficients. The results indicated a significant difference between the two correlation values $(z=1.87$, $p<0.05)$. 


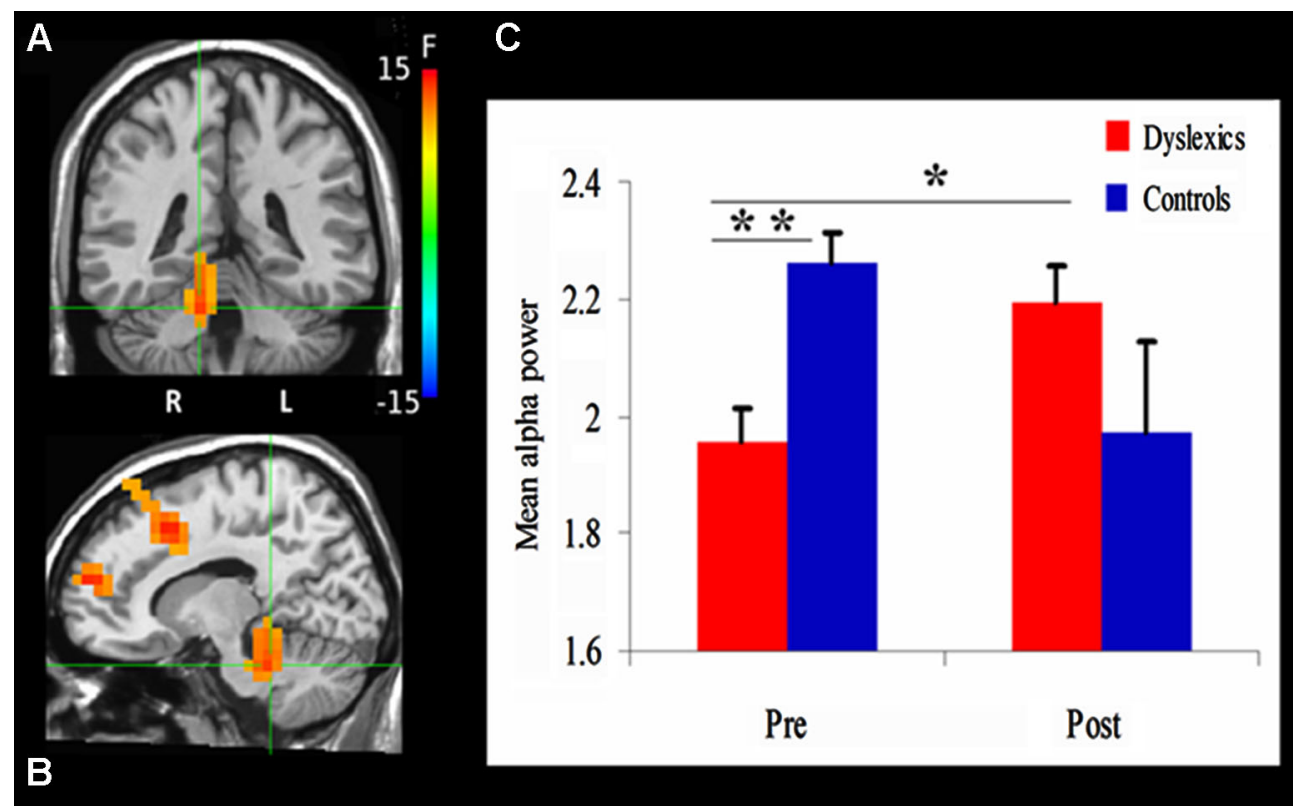

FIGURE 3 | Changes in alpha power. (A) and (B) demonstrate the significant clusters resulting from the Group (dyslexics, controls) by Training (pre-training, post-training) interaction. Voxels are colored by the $F$ statistics, overlaid on coronal (A) and sagittal (B) views. The statistical map is thresholded at $p<$
0.0025 in addition to a cluster size threshold of 20 voxels. The focus point (green cross) is positioned in the right culmen (Talairach coordinate: $12,-37$, -22). (C) The bar graph shows alpha power as a function of Group and Training (mean + SEM). * $p=0.01 ;{ }^{*} p=0.001$.

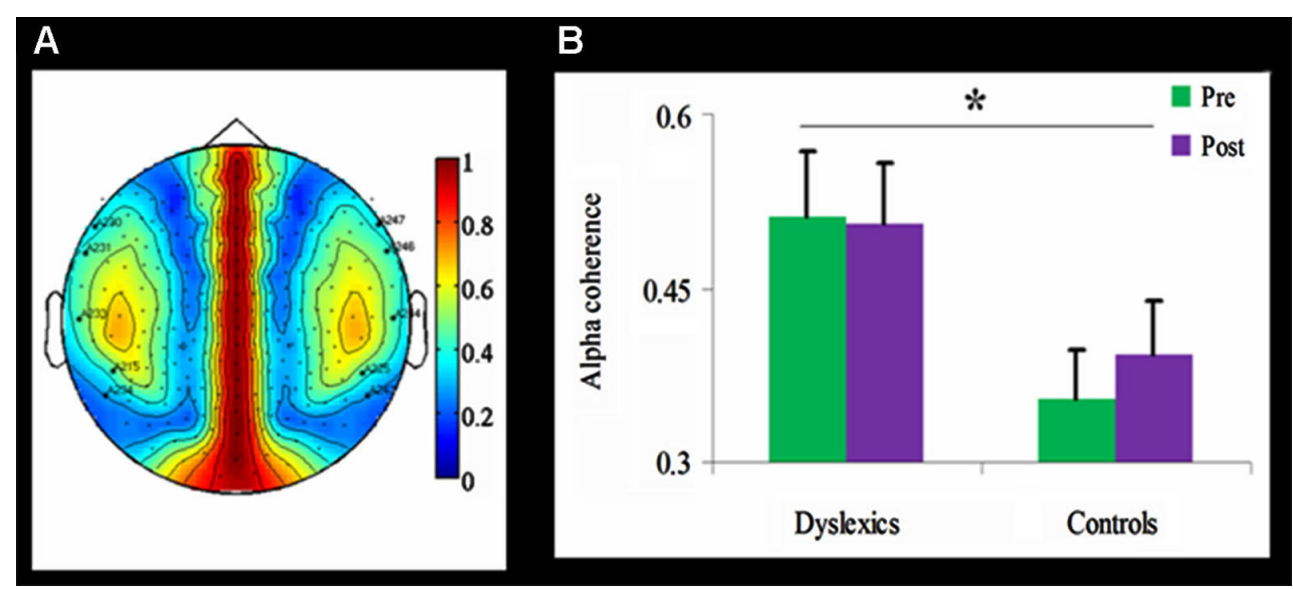

FIGURE 4 | Alpha coherence in the dyslexic and control groups. (A) Group differences in inter-hemispheric alpha coherence. The coherence was higher over temporal channels in the dyslexic group compared with the control group (* $p<0.01$, uncorrected). (B) Temporal alpha coherence as a function of Group and Training (mean + SEM), demonstrating significant group differences between the dyslexic and control groups $\left(^{*} p<0.01\right.$, uncorrected), as well as a null effect of the training in the dyslexic group and a trend toward an increase in alpha coherence in the control group.

\section{DISCUSSION}

Our results contribute two novel findings with regards to the cerebellar involvement in dyslexia: First, we show that cerebellar alpha activity prior to training is lower in dyslexics compared to controls. Second, a 4-week training program enhanced cerebellar alpha activity in dyslexics, but not in controls. Two other important findings are reported here for the first time: First, QMT over a period of 4 weeks improves reading speed in adults, and second, the improvement in reading performance is associated with increase in temporal alpha coherence in the dyslexic group. Below, we discuss these results in the context of different approaches to dyslexia and examine the possible role of the cerebellum in this neurodevelopmental disorder.

\section{OMT ENHANCES PERFORMANCE IN A SPEEDED READING TASK}

This study was inspired by the controversial body of research that examines the connection between reading and the sensorimotor 


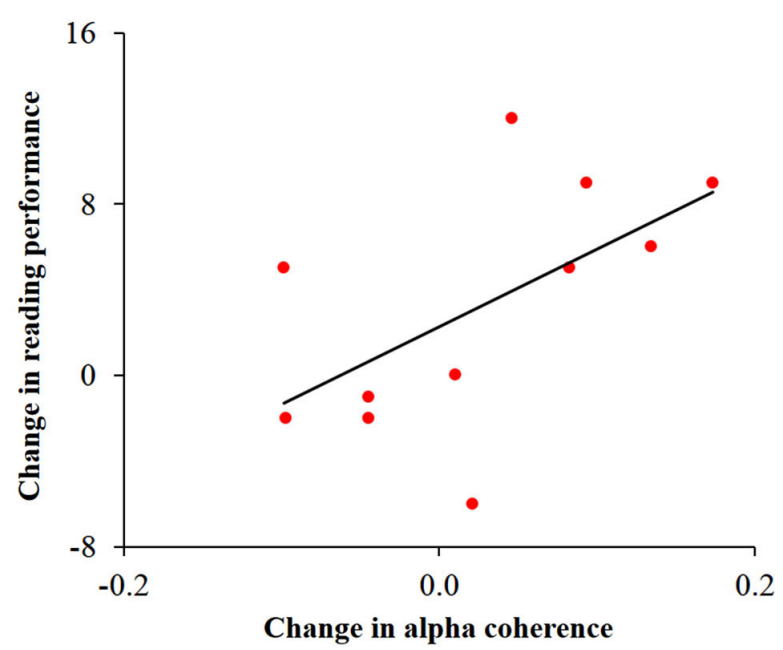

FIGURE 5 | Correlation between change in temporal alpha coherence and change in reading performance in the dyslexic group. Change in alpha coherence, calculated by the subtraction of pre- from post-training, was positively correlated with the change in number of words read correctly in $30 \mathrm{~s}(r=0.58, p<0.05)$

systems (e.g., Flöel et al., 2003; Pulvermüller, 2005), in the context of novel discoveries about the benefit of daily sensorimotor practice for cognition (Ben-Soussan et al., 2013). We found improved reading skills in both groups as a result of 4-week QMT. Commonly, experimental studies attempt to enhance reading abilities and phonological functions by providing a training program for the target skill. Here we show that sensorimotor training might be beneficial for improving reading skills even though the practice relies on faculties that are not directly related to reading. Indeed, the QMT is based on a series of motor responses to verbal commands, which involve functions such as spatial cognition and response inhibition (Ben-Soussan et al., 2014). QMT-related improvement in the speeded reading task was found using different stimulus lists at each time point (pre- and posttraining) and is thus considered to result from QMT and not from test-retest effects. This finding is also in agreement with previous results showing cognitive improvement in non-dyslexics adults even following short term QMT (Ben-Soussan et al., 2013, 2014).

In addition to group differences in reading score measured at baseline, a trend of a lower score in the phonological fluency task was observed pre-training in dyslexics compared to controls. This trend was not observed following 4 weeks of daily QMT, suggesting that QMT helped in normalizing the performance on this task. Again, the use of different categories at each time point (pre- and post-training) provided support to the interpretation that it is probably the QMT that normalized performance and not the repetition of the task. In addition, no differences were found between the groups in semantic fluency, neither before nor after training. This supports the view that dyslexia is more related to phonological than to semantic impairment (Leggio et al., 2000).

\section{OMT ENHANCES CEREBELLAR ALPHA POWER IN DYSLEXIC ADULTS}

In line with our hypothesis, cerebellar alpha power was significantly lower in the dyslexic group prior to training in comparison to the control group (see Figure 3C). Importantly, following 4 weeks of daily QMT, we found that cerebellar alpha significantly increased in the dyslexic group in the right culmen, a region which has been previously reported to be related to language processing (Luke et al., 2002; Pernet et al., 2009a,b; Rudner et al., 2013). This finding may reflect the role of the cerebellum as a general timing mechanism for both sensorimotor and cognitive processes (Ivry, 1997; Tesche and Karhu, 2000; Ivry et al., 2002; Tesche et al., 2007), such as the acquisition of sensorimotor skills and response readiness (Martin et al., 2006). It might also be linked to the critical involvement of the cerebellum in the coordination of smooth movements, maintenance of balance and posture, visually guided movements and motor learning (for review see Manto et al., 2012), which are inherent components of the QMT.

In addition to cerebellar changes, we found differences between dyslexics and controls in frontal alpha activity following 4 weeks of daily QMT. While alpha power in the left MFG and SMA significantly decreased in the control group, the dyslexic group showed increased alpha power in right SFG. These regions have been previously reported to be related to movement and language processing (Binder et al., 1997; Eckert et al., 2003; Neumann et al., 2004). Contrary to the dyslexics, the control group showed a trend towards a reduction in cerebellar alpha power; however, there was a notable increase of the control group's dispersion around the mean, which might account for the lack of statistical significance of this effect. In line with previous findings on motor practice, it is possible that the reduction of frontal and cerebellar activity indicates that practice became simpler as control of movement and coordination improve (Lacourse et al., 2004).

Previous work based on one session of training reported decreased frontal alpha activity in healthy young subjects (BenSoussan et al., 2013). This decreased frontal activity was mostly observed following simple motor training, indicating that changes in these regions might be related to motor learning as well as action observation and intention understanding (Exner et al., 2002; Dapretto et al., 2005). These results are compatible with Goldberg et al. (2006) who reported a complete segregation between self-related and sensorimotor activity in relevant cortical regions using functional neuroimaging. Their results showed that frontal regions were functionally inactive during sensorimotor tasks and active during self-engaged tasks. It is therefore possible that reduced activity of frontal regions at rest in controls signifies automaticity of sensorimotor components as a result of the repetition of the same sequence of QMT for 4 weeks.

\section{ALPHA COHERENCE IN DYSLEXIC ADULTS COMPARED TO CONTROLS}

Alpha coherence is important for cognitive and sensory processing (Weiss and Mueller, 2003; Ben-Soussan et al., 2013). Previously, EEG studies revealed increased coherence in dyslexic children, especially between temporal areas during rest (Shiota et al., 2000; Arns et al., 2007). Contrary to prior results showing increased inter-hemispheric alpha coherence following a single 
session of QMT (Ben-Soussan et al., 2013), in the current study neither group showed a significant increase in alpha coherence following one month of daily QMT. It should be noted that the previous results were obtained using EEG and not MEG. In fact, calculating connectivity from sensor level recordings is not straightforward, as these recordings are highly dependent on the effects of field spread. In other words, coherence measured by MEG reflects fewer sources because the spatial scale of the MEG sensors is smaller resulting in inflated estimates. Moreover, EEG and MEG are different in their sensitivity to radial and tangential dipoles (Srinivasan et al., 2007). This points to the necessity to integrate different methods in the study of training-induced plasticity.

Importantly, in the current study coherence analysis confirmed increased inter-hemispheric alpha coherence in the dyslexic group compared to the control group across time points. The increased inter-hemispheric coherence, especially between the temporal areas, may reflect the connection between left and right superior temporal sulci, which are considered to be necessary for phonological processing (Hickok and Poeppel, 2004). These findings converge with independent data from diffusion imaging showing that children with lower phonological and reading skills have higher anisotropy in temporal-callosal fiber tracts (Ben-Shachar et al., 2007; Dougherty et al., 2007).

Consequently, we propose that the increased coherence found in the dyslexic group may reflect a compensation mechanism (Roberts and Kraft, 1989; Arns et al., 2007). This suggestion further accords with the view that both left and right posterior superior temporal cortices are required for phonological processing (Hickok and Poeppel, 2007). Indeed, earlier models of dyslexia promoted the premise that complex cognitive functions, such as the translation of graphic symbols into a phonemic code, depend on component processes from both cerebral hemispheres, and that at least some subtypes of dyslexia may be due to abnormal inter-hemispheric communication (Gazzaniga, 1973; Gladstone and Best, 1985; Wolff et al., 1990). The association between change in coherence and reading performance revealed a significant positive correlation only in the dyslexic group, suggesting that the underlying mechanisms of improved reading observed in this study are connected with increased inter-hemispheric communication in the alpha range. Due to the low power of the correlation analysis $(N=11)$ and the nonsignificant effect of training on alpha coherence, this finding should be treated as suggestive, and should be tested in future larger MEG studies of developmental dyslexia. Nonetheless, the positive correlation reveals that participants who showed higher improvement of speeded reading also demonstrated increased bilateral temporal alpha coherence, in addition to the general increase in coherence observed in dyslexia. Some researchers aimed at normalizing brain activity (and consequently ameliorating behavioral and cognitive deficits) in various developmental disorders by suppressing hyper-connectivity (Pineda et al., 2012). Similarly, in stroke rehabilitation, applying brain stimulation to inhibit inappropriate activity of non-specialized areas has been argued to offer an effective avenue of treatment (Naeser et al., 2005). However, ameliorating cognitive deficits in developmental disorders may not necessarily be achieved through suppressing abnormal connectivity, because the observed hyper-connectivity does not necessarily reflect a dysfunction (Arns et al., 2007). Indeed, findings from neurofeedback training show that, contrary to the expected effects, 6 months of training induced an increase in alpha coherence, which might be related to improved attention (Breteler et al., 2010).

\section{TOWARDS A NEW APPROACH TO UNDERSTANDING AND TREATING DYSLEXIA}

Existing methods of treating dyslexia usually rely on phonetic and reading materials which aim at dealing directly with the linguistic impairments. Nevertheless, dyslexia, as well as other developmental disorders, should not be interpreted as being impairments in a single cognitive process (Castles and Coltheart, 1993; Pernet et al., 2009a). These cognitive impairments should rather be regarded as the endpoint of an abnormal developmental process, reflecting the interactions of multiple potentially deficient processes as well as compensatory processes (Thomas and Karmiloff-Smith, 2002). The current study attempted to investigate dyslexia-related differences in specific regions, in inter-hemispheric coherence, and in response to intervention. In this way, the differences between groups in the training-induced electrophysiological effects may provide further insight into the deficient and compensatory processes that characterize dyslexia.

In line with our results, we suggest that both the deficient cerebellar alpha power and possibly compensatory alpha coherence may be connected to the cerebellum's role as a generator of alpha activity, and that sensorimotor training may lead to cerebellar plasticity which could eventually rebalance the system. In this respect, altered cerebellar oscillatory activity may be the source of the deficit in dyslexia since it could be viewed as a neural system that mediates cortical communication (Andres et al., 1999; Silberstein et al., 2003). Our preliminary findings also disclose that sensorimotor training can be a practical intervention in dyslexia because of its potential to facilitate cerebellar oscillatory activity. Exploring how neuronal oscillation and cerebellar function change as a result of training may have valuable implications for educational neuroscience.

\section{LIMITATIONS}

The current study is a preliminary attempt to examine empirically the question of system modulation, which is required for improving reading in dyslexia. The main limitations of the current study are the small sample size and the use of only one training paradigm. The choice of QMT was made based on previous studies in which it was demonstrated that cognitive changes, namely increased creativity and improved spatial cognition, are QMT specific, and are not observed in two control groups (BenSoussan et al., 2013, 2014). In the future, a study on a larger sample that includes several training regimes may extend the current results. In future research, it would be important to include a passive control group; in particular, a dyslexic passive control group would ensure that any test-retest effects that were controlled for with normal-readers and with the two different versions of the tasks are not different in participants with dyslexia. 
So far, EEG studies have generally avoided studying cerebellar function because of the complex folding of the cerebellar cortex. As for MEG, signals can be obtained from the cerebellum especially within the alpha range (Ivry, 2000; Park et al., 2011). However, source localization makes it difficult to distinguish between signals arising in the cerebellar cortex and deep nuclei. Thus, our results should be interpreted keeping these limitations in mind. Regarding the coherence analysis, the statistical significance was not corrected for 59 comparisons and should be therefore evaluated with caution. However, since no previous study has shown similar left-right coherence effects it was impossible for us to focus on channels of interest and reduce the number of multiple comparisons. The results we report here can therefore be considered as exploratory, and should be confirmed in future studies. We expect that future studies will utilize independent imaging methods in order to examine the role of the cerebellum in reading and dyslexia, and the impact of QMT on cerebellar activity and connectivity.

\section{CONCLUSIONS}

The current MEG study is in line with previous studies suggesting that dyslexia may be related to cerebellar dysfunction. Four weeks of daily QMT enhances reading performance and cerebellar alpha oscillations in dyslexic participants. In addition, improved reading performance in dyslexics correlates with inter-hemispheric temporal alpha coherence. Our results suggest that cerebellar impairment in dyslexia can be modulated by sensorimotor training. Most importantly, the investigation of training-induced effects on reading performance provides a unique opportunity to gain insight into the relation between behavioral and neuronal changes. A better understanding of the functional coordination between cortical regions and the cerebellum would be necessary to pinpoint some of the underlying sources of dyslexia and to create training paradigms for clinical purposes. The current study provides an important step in bringing together different approaches to study the sources and treatment of dyslexia and the scientific value of sensorimotor training.

\section{ACKNOWLEDGMENTS}

We would like to thank the participants who let us examine their minds and brains. This study was supported by the Italy-Israel R\&D Cooperation Program (Number 44186) awarded to Joseph Glicksohn and Tal Dotan Ben-Soussan and by the Israeli Center of Research Excellence (I-CORE) in Cognition (I-CORE Program $51 / 11)$.

\section{REFERENCES}

Akshoomoff, N. A., Courchesne, E., Press, G. A., and Iragui, V. (1992). Contribution of the cerebellum to neuropsychological functioning: evidence from a case of cerebellar degenerative disorder. Neuropsychologia 30, 315-328. doi: 10. 1016/0028-3932(92)90105-u

Andres, F. G., Mima, T., Schulman, A. E., Dichgans, J., Hallett, M., and Gerloff, C. (1999). Functional coupling of human cortical sensorimotor areas during bimanual skill acquisition. Brain 122, 855-870. doi: 10.1093/brain/122.5.855

Appollonio, I. M., Grafman, J., Schwartz, V., Massaquoi, S., and Hallett, M. (1993). Memory in patients with cerebellar degeneration. Neurology 43, 1536-1536. doi: $10.1212 / \mathrm{wnl} .43 .8 .1536$
Arns, M., Peters, S., Breteler, R., and Verhoeven, L. (2007). Different brain activation patterns in dyslexic children: evidence from EEG power and coherence patterns for the double-deficit theory of dyslexia. J. Integr. Neurosci. 6, 175-190. doi: 10.1142/s0219635207001404

Basar, E., Schurmann, M., Basar-Eroglu, C., and Karakas, S. (1997). Alpha oscillations in brain functioning: an integrative theory. Int. J. Psychophysiol. 26, 5-29. doi: 10.1016/s0167-8760(97)00753-8

Ben-Shachar, M., Dougherty, R. F., and Wandell, B. A. (2007). White matter pathways in reading. Curr. Opin. Neurobiol. 17, 258-270. doi: 10.1016/j.conb. 2007.03.006

Ben-Soussan, T. D., Berkovich-Ohana, A., Glicksohn, J., and Goldstein, A. (2014). A suspended act: increased reflectivity and gender-dependent electrophysiological change following Quadrato Motor Training. Front. Psychol. 5:55. doi: 10. 3389/fpsyg.2014.00055

Ben-Soussan, T. D., Glicksohn, J., Goldstein, A., Berkovich-Ohana, A., and Donchin, O. (2013). Into the square and out of the box: the effects of Quadrato Motor Training on creativity and alpha Coherence. PLoS One 8:e55023. doi: 10. 1371/journal.pone.0055023

Binder, J. R., Frost, J. A., Hammeke, T. A., Cox, R. W., Rao, S. M., and Prieto, T. (1997). Human brain language areas identified by functional magnetic resonance imaging. J. Neurosci. 17, 353-362.

Bradley, L., and Bryant, P. E. (1983). Categorizing sounds and learning to read: a causal connection. Nature 301, 419-421. doi: 10.1038/301419a0

Breteler, M. H., Arns, M., Peters, S., Giepmans, I., and Verhoeven, L. (2010). Improvements in spelling after QEEG-based neurofeedback in dyslexia: a randomized controlled treatment study. Appl. Psychophysiol. Biofeedback 35, 5-11. doi: 10.1007/s10484-009-9105-2

Buckner, R. L. (2013). The cerebellum and cognitive function: 25 years of insight from anatomy and neuroimaging. Neuron 80, 807-815. doi: 10.1016/j.neuron. 2013.10.044

Bunge, S. A., Ochsner, K. N., Desmond, J. E., Glover, G. H., and Gabrieli, J. D. (2001). Prefrontal regions involved in keeping information in and out of mind. Brain 124, 2074-2086. doi: 10.1093/brain/124.10.2074

Castles, A., and Coltheart, M. (1993). Varieties of developmental dyslexia. Cognition 47, 149-180. doi: 10.1016/0010-0277(93)90003-e

Cox, R. W. (2012). AFNI: what a long strange trip it's been. Neuroimage 62, $743-$ 747. doi: 10.1016/j.neuroimage.2011.08.056

Criscimagna-Hemminger, S. E., Donchin, O., Gazzaniga, M. S., and Shadmehr, R. (2002). Learning dynamics of reaching movements generalizes from dominant to non-dominant arm. J. Neurophysiol. 89, 168-176. doi: 10.1152/jn.00622.2002

Dapretto, M., Davies, M. S., Pfeifer, J. H., Scott, A. A., Sigman, M., Bookheimer, S. Y., et al. (2005). Understanding emotions in others: mirror neuron dysfunction in children with autism spectrum disorders. Nat. Neurosci. 9, 28-30. doi: 10. 1038/nn 1611

De Kleine, E., and Verwey, W. B. (2009). Motor learning and chunking in dyslexia. J. Mot. Behav. 41, 331-338. doi: 10.3200/jmbr.41.4.331-338

De Zeeuw, C. I., Hoebeek, F. E., Bosman, L. W., Schonewille, M., Witter, L., and Koekkoek, S. K. (2011). Spatiotemporal firing patterns in the cerebellum. Nat. Rev. Neurosci. 12, 327-344. doi: 10.1038/nrn3011

Deffenbacher, K. E., Kenyon, J. B., Hoover, D. M., Olson, R. K., Pennington, B. F., DeFries, J. C., et al. (2004). Refinement of the 6p21. 3 quantitative trait locus influencing dyslexia: linkage and association analyses. Hum. Genet. 115, 128 138. doi: 10.1007/s00439-004-1126-6

Donchin, O., Francis, J. T., and Shadmehr, R. (2003). Quantifying generalization from trial-by-trial behavior of adaptive systems that learn with basis functions: theory and experiments in human motor control. J. Neurosci. 23, 9032-9045.

Dougherty, R. F., Ben-Shachar, M., Deutsch, G. K., Hernandez, A., Fox, G. R., and Wandell, B. A. (2007). Temporal-callosal pathway diffusivity predicts phonological skills in children. Proc. Natl. Acad. Sci. U S A 104, 8556-8561. doi: 10. 1073/pnas.0608961104

Dufor, O., Serniclaes, W., Sprenger-Charolles, L., and Démonet, J. F. (2007). Topdown processes during auditory phoneme categorization in dyslexia: a PET study. Neuroimage 34, 1692-1707. doi: 10.1016/j.neuroimage.2006.10.034

Eckert, M. A., Leonard, C. M., Richards, T. L., Aylward, E. H., Thomson, J., and Berninger, V. W. (2003). Anatomical correlates of dyslexia: frontal and cerebellar findings. Brain 126, 482-494. doi: 10.1093/brain/awg026

Exner, C., Koschack, J., and Irle, E. (2002). The differential role of premotor frontal cortex and basal ganglia in motor sequence learning: evidence from focal basal ganglia lesions. Learn. Mem. 9, 376-386. doi: 10.1101/lm.48402 
Flöel, A., Ellger, T., Breitenstein, C., and Knecht, S. (2003). Language perception activates the hand motor cortex: implications for motor theories of speech perception. Eur. J. Neurosci. 18, 704-708. doi: 10.1046/j.1460-9568.2003. 02774.x

Friston, K. J., Ashburner, J. T., Kiebel, S. J., Nichols, T. E., and Penny, W. D. (2007). Statistical Parametric Mapping: The Analysis of Functional Brain Images. London: Academic Press.

Gabrieli, J. D. (2009). Dyslexia: a new synergy between education and cognitive neuroscience. Science 325, 280-283. doi: 10.1126/science.1171999

Galaburda, A. M., LoTurco, J., Ramus, F., Fitch, R. H., and Rosen, G. D. (2006). From genes to behavior in developmental dyslexia. Nat. Neurosci. 9, 1213-1217. doi: $10.1038 / \mathrm{nn} 1772$

Gazzaniga, M. S. (1973). Brain theory and minimal brain dysfunction. Ann. N Y Acad. Sci. 205, 89-92. doi: 10.1111/j.1749-6632.1973.tb43166.x

Genow, A., Hummel, C., Scheler, G., Hopfengärtner, R., Kaltenhäuser, M., Buchfelder, M., et al. (2004). Epilepsy surgery, resection volume and MSI localization in lesional frontal lobe epilepsy. Neuroimage 21, 444-449. doi: 10. 1016/j.neuroimage.2003.08.029

Gladstone, M., and Best, C. T. (1985). "Developmental dyslexia: the potential role of interhemispheric collaboration in reading acquisition," in Hemispheric Function Collaboration in the Child, ed C. T. Best (San Francisco: Academic Press), 87118.

Goldberg, I. I., Harel, M., and Malach, R. (2006). When the brain loses its self: prefrontal inactivation during sensorimotor processing. Neuron 50, 329-339. doi: 10.1016/j.neuron.2006.03.015

Goldman, R. I., Stern, J. M., Engel, J. Jr., and Cohen, M. S. (2002). Simultaneous EEG and fMRI of the alpha rhythm. Neuroreport 13, 2487-2492. doi: 10. 1097/00001756-200212200-00022

Goswami, U. (2011). A temporal sampling framework for developmental dyslexia. Trends Cogn. Sci. 15, 3-10. doi: 10.1016/j.tics.2010.10.001

Güntekin, B., and Basar, E. (2010). A new interpretation of P300 responses upon analysis of coherences. Cogn. Neurodynm. 4, 107-118. doi: 10.1007/s11571-0109106-0

Hickok, G., and Poeppel, D. (2004). Dorsal and ventral streams: a framework for understanding aspects of the functional anatomy of language. Cognition 92, 6799. doi: 10.1016/j.cognition.2003.10.011

Hickok, G., and Poeppel, D. (2007). The cortical organization of speech processing. Nat. Rev. Neurosci. 8, 393-402. doi: 10.1038/nrn2113

Hickok, G., Houde, J., and Rong, F. (2011). Sensorimotor integration in speech processing: computational basis and neural organization. Neuron 69, 407-422. doi: 10.1016/j.neuron.2011.01.019

Hölzel, B. K., Carmody, J., Vangel, M., Congleton, C., Yerramsetti, S. M., Gard, T., et al. (2011). Mindfulness practice leads to increases in regional brain gray matter density. Psychiatry Res. 191, 36-43. doi: 10.1016/j.pscychresns.2010. 08.006

Ivry, R. (1997). Cerebellar timing systems. Int. Rev. Neurobiol. 41, 555-573. doi: 10. 1016/s0074-7742(08)60370-0

Ivry, R. (2000). Exploring the role of the cerebellum in sensory anticipation and timing: commentary on Tesche and Karhu. Hum. Brain Mapp. 9, 115-118. doi: 10.1002/(sici)1097-0193(200003)9:3<115::aid-hbm1>3.3.co;2-x

Ivry, R. B., Spencer, R. M., Zelaznik, H. N., and Diedrichsen, J. (2002). The cerebellum and event timing. Ann. N Y Acad. Sci. 978, 302-317. doi: 10.1111/j. 1749-6632.2002.tb07576.x

Kanda, M., Nagamine, T., Ikeda, A., Ohara, S., Kunieda, T., Fujiwara, N., et al. (2000). Primary somatosensory cortex is actively involved in pain processing in human. Brain Res. 853, 282-289. doi: 10.1016/s0006-8993(99) 02274-x

Kavé, G. (2005). Phonemic fluency, semantic fluency and difference scores: normative data for adult Hebrew speakers. J. Clin. Exp. Neuropsychol. 27, 690-699. doi: 10.1080/13803390490918499

Kikuchi, M., Shitamichi, K., Yoshimura, Y., Ueno, S., Remijn, G. B., Hirosawa, T., et al. (2011). Lateralized theta wave connectivity and language performance in 2-to 5-year-old children. J. Neurosci. 31, 14984-14988. doi: 10.1523/jneurosci. 2785-11.2011

Lacourse, M. G., Turner, J. A., Randolph-Orr, E., Schandler, S. L., and Cohen, M. J. (2004). Cerebral and cerebellar sensorimotor plasticity following motor imagery-based mental practice of a sequential movement. J. Rehabil. Res. Dev. 41, 505-524. doi: 10.1682/jrrd.2004.04.0505
Leggio, M. G., Silveri, M. C., Petrosini, L., and Molinari, M. (2000). Phonological grouping is specifically affected in cerebellar patients: a verbal fluency study. J. Neurol. Neurosurg. Psychiatry 69, 102-106. doi: 10.1136/jnnp.69. 1.102

Lehnertz, K., Ansmann, G., Bialonski, S., Dickten, H., Geier, C., and Porz, S. (2014). Evolving networks in the human epileptic brain. Physica D 267, 7-15. doi: 10. 1016/j.physd.2013.06.009

Leiner, H. C., Leiner, A. L., and Dow, R. S. (1993). Cognitive and language functions of the human cerebellum. Trends Neurosci. 16, 444-447. doi: 10.1016/01662236(93)90072-t

Levy-Drori, S., and Henik, A. (2006). Concreteness and context availability in lexical decision tasks. Am. J. Psychol. 119, 45-65. doi: 10.2307/20445318

Luke, K. K., Liu, H. L., Wai, Y. Y., Wan, Y. L., and Tan, L. H. (2002). Functional anatomy of syntactic and semantic processing in language comprehension. Hum. Brain Mapp. 16, 133-145. doi: 10.1002/hbm.10029

Manto, M., Bower, J. M., Conforto, A. B., Delgado-García, J. M., da Guarda, S. N. F., Gerwig, M., et al. (2012). Consensus paper: roles of the cerebellum in motor control-the diversity of ideas on cerebellar involvement in movement. Cerebellum 11, 457-487. doi: 10.1007/s12311-011-0331-9

Martin, T., Houck, J. M., Bish, J. P., Kičić, D., Woodruff, C. C., Moses, S. N., et al. (2006). MEG reveals different contributions of somatomotor cortex and cerebellum to simple reaction time after temporally structured cues. Hum. Brain Mapp. 27, 552-561. doi: 10.1002/hbm.20200

Naeser, M. A., Martin, P. I., Nicholas, M., Baker, E. H., Seekins, H., Kobayashi, M., et al. (2005). Improved picture naming in chronic aphasia after TMS to part of right Broca's area: an open-protocol study. Brain Lang. 93, 95-105. doi: 10. 1016/j.bandl.2004.08.004

Neumann, K., Euler, H. A., Gudenberg, A. W. V., Giraud, A. L., Lanfermann, H., Gall, V., et al. (2004). The nature and treatment of stuttering as revealed by fMRI: a within-and between-group comparison. J. Fluency Disord. 28, 381-410. doi: 10.1016/j.jfludis.2003.07.003

Nicolson, R. I., Fawcett, A. J., and Dean, P. (2001). Developmental dyslexia: the cerebellar deficit hypothesis. Trends Neurosci. 24, 508-511. doi: 10.1016/s01662236(00)01896-8

Nicolson, R. I., Fawcett, A. J., Berry, E. L., Jenkins, I. H., Dean, P., and Brooks, D. J. (1999). Association of abnormal cerebellar activation with motor learning difficulties in dyslexic adults. Lancet 353, 1662-1667. doi: 10.1016/s01406736(98)09165-X

Oganian, Y., and Ahissar, M. (2012). Poor anchoring limits dyslexics' perceptual, memory and reading skills. Neuropsychologia 50, 1895-1905. doi: 10.1016/j. neuropsychologia.2012.04.014

Oostenveld, R., Fries, P., Maris, E., and Schoffelen, J. M. (2011). FieldTrip: open source software for advanced analysis of MEG, EEG and invasive electrophysiological data. Comput. Intell. Neurosci. 2011:156869. doi: 10.1155/2011/ 156869

Orton, S. T. (1937). Reading, Writing and Speech Problems in Children. New York: Norton.

Osipova, D., Ahveninen, J., Kaakkola, S., Jääskeläinen, I. P., Huttunen, J., and Pekkonen, E. (2003). Effects of scopolamine on MEG spectral power and coherence in elderly subjects. Clin. Neurophysiol. 114, 1902-1907. doi: 10.1016/s13882457(03)00165-2

Park, H., Kang, E., Kang, H., Kim, J. S., Jensen, O., Chung, C. K., et al. (2011). Cross-frequency power correlations reveal the right superior temporal gyrus as a hub region during working memory maintenance. Brain Connect. 1, 460-472. doi: 10.1089/brain.2011.0046

Pernet, C., Andersson, J., Paulesu, E., and Demonet, J. F. (2009a). When all hypotheses are right: a multifocal account of dyslexia. Hum. Brain Mapp. 30, 2278-2292. doi: 10.1002/hbm.20670

Pernet, C., Poline, J., Demonet, J., and Rousselet, G. (2009b). Brain classification reveals the right cerebellum as the best biomarker of dyslexia. BMC Neurosci. 10:67. doi: 10.1186/1471-2202-10-67

Pineda, J. A., Juavinett, A., and Datko, M. (2012). Self-regulation of brain oscillations as a treatment for aberrant brain connections in children with autism. Med. Hypotheses 79, 790-798. doi: 10.1016/j.mehy.2012.08.031

Pulvermüller, F. (2005). Brain mechanisms linking language and action. Nat. Rev. Neurosci. 6, 576-582. doi: 10.1038/nrn1706

Rack, J. P., Snowling, M. J., and Olson, R. K. (1992). The nonword reading deficit in developmental dyslexia: a review. Read. Res. Q. 27, 29-53. 
Ramus, F. (2004). Neurobiology of dyslexia: a reinterpretation of the data. Trends Neurosci. 27, 720-726. doi: 10.1016/j.tins.2004.10.004

Ramus, F., Pidgeon, E., and Frith, U. (2003). The relationship between motor control and phonology in dyslexic children. J. Child Psychol. Psychiatry 44, 712722. doi: 10.1111/1469-7610.00157

Rao, S. M., Mayer, A. R., and Harrington, D. L. (2001). The evolution of brain activation during temporal processing. Nat. Neurosci. 4, 317-323. doi: 10. $1038 / 85191$

Reid, A. A., Szczerbinski, M., Iskierka-Kasperek, E., and Hansen, P. (2007). Cognitive profiles of adult developmental dyslexics: theoretical implications. Dyslexia 13, 1-24. doi: $10.1002 /$ dys.321

Reynolds, D., and Nicolson, R. I. (2007). Follow-up of an exercise-based treatment for children with reading difficulties. Dyslexia 13, 78-96. doi: 10.1002/ dys. 331

Reynolds, D., Nicolson, R. I., and Hambly, H. (2003). Evaluation of an exercisebased treatment for children with reading difficulties. Dyslexia 9, 48-71. doi: 10. $1002 /$ dys. 235

Roberts, T. A., and Kraft, R. H. (1989). Developmental differences in the relationship between reading comprehension and hemispheric alpha patterns: an EEG study. J. Educ. Psychol. 81, 322-328. doi: 10.1037/0022-0663.81.3.322

Robinson, S. E., and Vrba, J. (1999). "Functional neuroimaging by synthetic aperture magnetometry (SAM)," in Recent Advances in Biomagnetism, eds T. Yoshimoto, M. Kotani, S. Kuriki, H. Karibe and N. Nakasato (Sendai: Tohuku University Press), 302-305.

Rudner, M., Karlsson, T., Gunnarsson, J., and Rönnberg, J. (2013). Levels of processing and language modality specificity in working memory. Neuropsychologia 51, 656-666. doi: 10.1016/j.neuropsychologia.2012.12.011

Salmelin, R. (2007). Clinical neurophysiology of language: the MEG approach. Clin. Neurophysiol. 118, 237-254. doi: 10.1016/j.clinph.2006.07.316

Schmahmann, J. D. (2004). Disorders of the cerebellum: ataxia, dysmetria of thought and the cerebellar cognitive affective syndrome. J. Neuropsychiatry Clin. Neurosci. 16, 367-378. doi: 10.1176/appi.neuropsych.16.3.367

Sekihara, K., Nagarajan, S. S., Poeppel, D., and Marantz, A. (2004). Asymptotic SNR of scalar and vector minimum-variance beamformers for neuromagnetic source reconstruction. IEEE Trans. Biomed. Eng. 51, 1726-1734. doi: 10.1109/tbme. 2004.827926

Shaywitz, S. E., Morris, R., and Shaywitz, B. A. (2008). The education of dyslexic children from childhood to young adulthood. Annu. Rev. Psychol. 59, 451-475. doi: 10.1146/annurev.psych.59.103006.093633

Shiota, M., Koeda, T., and Takeshita, K. (2000). Cognitive and neurophysiological evaluation of Japanese dyslexia. Brain Dev. 22, 421-426. doi: 10.1016/s03877604(00)00167-4

Silberstein, R. B. (2006). Dynamic sculpting of brain functional connectivity and mental rotation aptitude. Prog. Brain Res. 159, 63-76. doi: 10.1016/s00796123(06)59005-3

Silberstein, R. B., Danieli, F., and Nunez, P. L. (2003). Fronto-parietal evoked potential synchronization is increased during mental rotation. Neuroreport 14 , 67-71. doi: 10.1097/00001756-200301200-00013

Srinivasan, R., Winter, W. R., Ding, J., and Nunez, P. L. (2007). EEG and MEG coherence: measures of functional connectivity at distinct spatial scales of neocortical dynamics. J. Neurosci. Methods 166, 41-52. doi: 10.1016/j.jneumeth. 2007.06.026
Stein, J. (2001). The magnocellular theory of developmental dyslexia. Dyslexia 7 , 12-36. doi: 10.1002/dys.186

Stein, J., and Walsh, V. (1997). To see but not to read; the magnocellular theory of dyslexia. Trends Neurosci. 20, 147-152. doi: 10.1016/s0166-2236(96)01005-3

Stoodley, C. J., and Schmahmann, J. D. (2009). Functional topography in the human cerebellum: a meta-analysis of neuroimaging studies. Neuroimage 44, 489-501. doi: 10.1016/j.neuroimage.2008.08.039

Stoodley, C. J., and Stein, J. F. (2011). The cerebellum and dyslexia. Cortex 47, 101116. doi: 10.1016/j.cortex.2009.10.005

Swinnen, S. P. (2002). Intermanual coordination: from behavioural principles to neural-network interactions. Nat. Rev. Neurosci. 3, 348-359. doi: 10. $1038 / \mathrm{nrn} 807$

Tal, I., and Abeles, M. (2013). Cleaning MEG artifacts by external cues. J. Neurosci. Methods 217, 31-38. doi: 10.1016/j.jneumeth.2013.04.002

Tallal, P., Miller, S. L., Bedi, G., Byma, G., Wang, X., Nagarajan, S. S., et al. (1996). Language comprehension in language-learning impaired children improved with acoustically modified speech. Science $271,81-84$. doi: 10.1126/science.271. 5245.81

Tesche, C. D., Moses, S. N., Houck, J. M., Martin, T., Hanlon, F. M., Jackson, E., et al. (2007). Dynamics of frontal and cerebellar activation during aversive conditioning: an MEG study. Int. Congr. Ser. 1300, 437-440. doi: 10.1016/j.ics. 2007.02.057

Tesche, C. D., and Karhu, J. J. (2000). Anticipatory cerebellar responses during somatosensory omission in man. Hum. Brain Mapp. 9, 119-142. doi: 10. 1002/(sici) 1097-0193(200003)9:3<119::aid-hbm2>3.3.co;2-i

Thomas, M., and Karmiloff-Smith, A. (2002). Are developmental disorders like cases of adult brain damage? Implications from connectionist modelling. Behav. Brain Sci. 25, 727-750. doi: 10.1017/s0140525x02000134

Weiss, S., and Mueller, H. M. (2003). The contribution of EEG coherence to the investigation of language. Brain Lang. 85, 325-343. doi: 10.1016/s0093$934 \mathrm{x}(03) 00067-1$

Wolff, P. H., Michel, G. F., Ovrut, M., and Drake, C. (1990). Rate and timing precision of motor coordination in developmental dyslexia. Dev. Psychol. 26, 349-359. doi: 10.1037/0012-1649.26.3.349

Conflict of Interest Statement: The authors declare that the research was conducted in the absence of any commercial or financial relationships that could be construed as a potential conflict of interest.

Received: 31 January 2014; accepted: 18 April 2014; published online: 09 May 2014. Citation: Ben-Soussan TD, Avirame K, Glicksohn J, Goldstein A, Harpaz Y and Ben-Shachar M (2014) Changes in cerebellar activity and inter-hemispheric coherence accompany improved reading performance following Quadrato Motor Training. Front. Syst. Neurosci. 8:81. doi: 10.3389/fnsys.2014.00081

This article was submitted to the journal Frontiers in Systems Neuroscience.

Copyright $\odot 2014$ Ben-Soussan, Avirame, Glicksohn, Goldstein, Harpaz and BenShachar. This is an open-access article distributed under the terms of the Creative Commons Attribution License (CC BY). The use, distribution or reproduction in other forums is permitted, provided the original author(s) or licensor are credited and that the original publication in this journal is cited, in accordance with accepted academic practice. No use, distribution or reproduction is permitted which does not comply with these terms. 